\title{
National Character and Economic Performance
}

\author{
Bijou Yang ${ }^{1} \&$ David Lester ${ }^{2}$ \\ ${ }^{1}$ School of Economics, LeBow College of Business, Drexel University, Philadephia, PA, USA \\ ${ }^{2}$ Stockton University, Galloway, NJ, USA \\ Correspondence: David Lester, Psychology Program, Stockton University, Galloway, NJ 08205, USA. Tel: \\ 609-652-4512. E-mail: lesterd@stockton.edu
}

Received: July 12, 2018

Accepted: August 5, 2018

Online Published: August 8, 2018

doi:10.5539/ijef.v10n9p9

URL: https://doi.org/10.5539/ijef.v10n9p9

\begin{abstract}
The present study explored whether the average scores on a personality test of the residents in 55 nations were associated with the gross domestic product per capita in the year 2000 and the growth in the GDP/capita from 2001-2005. Nations whose residents had higher score on a measure of neuroticism had a higher GDP/capita in 2000 , and nations whose residents had higher scores on a measure of agreeableness had lower growth in the GDP/capita from 2001 to 2005. This supports Lynn's hypothesis that national character might contribute to the prediction of the economic performance of nations.
\end{abstract}

Keywords: personality, GDP per capita, GDP, neuroticism

\section{Introduction}

In contrast to classical economic theory, which assumed that people will always make rational decisions, behavioral economics has drawn attention to the fact that people often deviate from rational behavior. While this has been demonstrated at the individual level of analysis (Lester \& Yang, 2009), it is not clear whether this is true at the aggregate level of analysis. The present study was designed to explore this at the national level.

Economic growth, the increase of a nation's income from one year to the next, is obviously determined by a number of factors, including the strength and stability of demand, the rate of technical progress, the growth and level of capital stock, international diffusion mechanisms, and structural changes in employment. Lynn (1991) pointed out, however, that these economic factors are not sufficient in themselves to explain economic growth. What might explain the residual variance? Lynn suggested that this may be a result of the psychological and sociological attributes of the population. Perhaps the level of motivation of the residents of nations or their level of education (Denison, 1967) might be relevant. Weber (1929) stressed the role of the Protestant work ethic. Schumpeter (1934) focused on the role of individual entrepreneurs. Wiener (1981) argued for the role of anti-business values in the society as a factor stunting economic growth.

McClelland (1976) proposed that the achievement motivation of people in a nation had a large impact on economic growth. McClelland devised training programs to increase the achievement motivation of individuals in under-developed nations, especially in those who were potential entrepreneurs, in order to demonstrate that those trained in his program achieved more economically than those who did not participate in his training program. McClelland found that the level of achievement motivation in children's textbooks in a sample of nations predicted the economic growth of those nations, suggesting that early influences on the children in a nation might have an important impact on their later behavior, including their economic activity.

"National character" refers to the possibility that the residents of different nations may differ in personality and attitudes. National character is typically measured by administering psychological tests to sample of the residents on a nation. Hofstede (2001) gave employees of IBM in 40 nations an inventory to measure five attitudes: power-distance, individualism, masculinity, uncertainty avoidance, and long-term orientation (www.geert-hofstede.com). Johnson and Lenartowicz (1998) devised a measure of economic freedom (based on indices of money and inflation, government operations and regulation, takings and discriminant taxation, and international exchange) and found that this measure was positively associated with Hofstede's measures of uncertainty avoidance and masculinity. In this study, therefore, the attitudes of the residents of nations were associated with economic variables, although, of course, the direction of causation cannot be determined from a correlational study. 
Lynn (1991) gave a personality and attitude test to college and university students in 43 countries to measure eight traits, including, work ethic, achievement motivation, need for mastery, competitiveness, achievement versus conformity, money beliefs, attitude toward saving, and occupational preferences. The strongest predictor of economic growth was the competitiveness scores from the countries, while work ethic, achievement motivation, and money attitudes were not significant predictors. Overall, scores on these scales accounted for half of the variance in economic growth for the period 1970-1985 $\left(R^{2}=0.50\right)$, and the association was strong in both developed countries and developing countries. The studies by Lynn and by Hofstede indicate that national character can be measured using personality and attitude tests and, in addition, that scores on these tests may be associated with economic variables.

There are thousands, of adjectives that can be used to describe people's personality but, to be useful, only a limited number of dimensions of personality are needed. Some proposals for these have been based on theory. For example, Eysenck (1994) based his three dimensions of personality (extraversion, neuroticism and psychoticism) on the structure of the central nervous system and its functioning. According to Eysenck, extraversion was determined by the level of excitation versus inhibition in the transmission of electrical impulses in the brain which, in turn, was controlled by the reticular activating system in the brain stem. Cloninger (1986) based his three dimensions of personality (harm-avoidance, reward dependence and novelty-seeking) on the level of three neurotransmitters in the central nervous system (serotonin, norepinephrine and dopamine).

There have been several "arm chair" (ex cathedra) proposals by psychologists, such as Cattell (1990) who proposed 16 dimensions of personality. A recent effort by Costa and McRae (1992) took an empirical approach by looking at the inter-correlation of scores on multiple personality tests and finding how many dimensions best described the correlation matrix. Their model is called the Big Five model and easily remembered by the mnemonic OCEAN. Each dimension is characterized by a set of traits.

O Openness: e.g., having wide interests, imaginative and insightful

C Conscientiousness: e.g., organized, thorough and planful

E Extraversion: e.g., talkative, energetic and assertive

A Agreeableness: e.g., sympathetic, kind and affectionate

$\mathrm{N}$ Neuroticism: e.g., tense, moody and anxious

Typical items are:

Are you someone who...

Is curious about many different things $(\mathrm{O})$

Is a reliable worker $(\mathrm{C})$

Generates a lot of enthusiasm (E)

Is helpful and unselfish with others (A)

Worries a lot $(\mathrm{N})$

In individuals, scores on these five personality dimensions are associated with many psychological variables and behaviors. For example, Furnham, Moutafi and Chamorro-Premuzic (2005) found that conscientiousness scores predicted intelligence test scores, while Seibert and Kraimer (2001) found that extraversion was associated with higher-income, greater success in one's career, and greater job satisfaction.

The aim of the present study was to explore whether these personality dimensions predict economic growth at the societal (aggregate) level, in the present case, nations of the world. Early attempts by McRae on this task obtained usable data from only 28 nations (McRae, 2002) and 46 nations (McRae \& Terracciano, 2005). Bartram (2013) obtained data for only 28 nations. McRae later collaborated on the most extensive attempt to collect data on the Big 5 personality traits from residents of nations which was coordinated by Schmitt and his colleagues. Schmitt, Allik, McRea, and Behet-Martinez (2007) obtained the cooperation of over 100 researchers in 56 nations to administer a Big 5 inventory to residents of their nations. All researchers administered the same 44-item inventory to at least 100 men and 100 women. The inventory was translated into the language of each nation, and the translations checked using a back-translation methodology. The final sample was 17,408 respondents. The major sources of the data were college students (44 nations), college students and community residents (10 nations) and community residents ( 2 nations). 
In previous research, Steel, Rinne and Fairweather (2012) found that, in multiple regressions, none of the OCEAN personality scores published by Schmitt, et al. were associated with two indices of innovation in the nations. The present study explored whether the national OCEAN personality scores were associated with national indices of economic performance and growth.

\section{Method}

Scores for the Big 5 traits for 55 nations were obtained from Schmitt, et al. (2007). Schmitt, et al. made an effort to include nations in all regions of the world in reasonable numbers. Data from Taiwan were not used since the World Bank does not provide economic data for Taiwan. Schmitt, et al. presented T-scores for the five personality traits (OCEAN) for each nation. T-scores are standardized scores with a mean of 50 and a standard deviation of 10. The annual growth rates in the real domestic product per capita for the period 2001-2005 were obtained from the World Bank (data.worldbank.org/indicator). The GDP (PPP) per capita in 2005 was obtained from www.nationmaster.com. The nations in the sample are shown in the Appendix.

\section{Results}

The associations between national measures of the Big 5 trait scores and economic performance for the 55 nations are shown in Table 1. Looking at the Pearson correlations (Table 1), the nations whose residents had higher levels of agreeableness had significantly lower economic growth from 2001 to 2005 . The GDP per capita in 2005 was associated with neuroticism (positively). The analyses were re-run for the 25 European nations in the sample (Table 1). Agreeableness was again the only statistically significant correlate of GDP per capita growth.

Table 1. Associations of Big 5 trait scores with economic performance

\begin{tabular}{|c|c|c|c|c|}
\hline \multicolumn{5}{|c|}{ Pearson Correlations } \\
\hline & \multicolumn{2}{|c|}{55 nations } & \multicolumn{2}{|c|}{25 European nations } \\
\hline & GDP/capita & $\%$ change GDP/capita & GDP/capita & $\%$ change GDP/capita \\
\hline & 2005 & $2001-2005$ & 2005 & $2001-2005$ \\
\hline $\mathrm{O}$ & -0.03 & -0.02 & +0.15 & -0.08 \\
\hline $\mathrm{C}$ & -0.23 & -0.23 & +0.28 & -0.32 \\
\hline $\mathrm{E}$ & +0.04 & +0.02 & -0.04 & +0.09 \\
\hline A & -0.21 & $-0.27 *$ & +0.34 & $-0.44 *$ \\
\hline $\mathrm{N}$ & $+0.27 *$ & -0.10 & +0.21 & -0.28 \\
\hline
\end{tabular}

$*$ two-tailed $<.05$.

In the multiple regressions for the 55 nations (Table 2), agreeableness and neuroticism predicted the GDP per capita growth (both negatively), while neuroticism predicted higher GDP per capita in 2005. After adding GDP per capita in the year 2005 as a control variable for the regression (Table 2), neuroticism and the GDP per capita in the year 2005 were the only significant predictors of the growth in the GDP per capita.

Table 2. Linear regressions (betas shown) [55 Nations]

\begin{tabular}{lccc}
\hline & GDP/capita & \% change in GDP/capita & \% change in GDP/capita \\
\hline $\mathrm{O}$ & -0.04 & +0.09 & +0.06 \\
$\mathrm{C}$ & -0.06 & -0.26 & -0.29 \\
$\mathrm{E}$ & +0.23 & -0.08 & -0.07 \\
$\mathrm{~A}$ & -0.06 & $-0.30 \#$ & -0.31 \\
$\mathrm{~N}$ & $+0.33 \#$ & $-0.42^{*} \#$ & $-0.37^{*} \#$ \\
$\mathrm{GDP} /$ capita & & & $-0.26 \#$ \\
$\mathrm{R}^{2}$ & 0.12 & 0.18 & 0.24 \\
\hline
\end{tabular}

\# significant in the backward multiple regression $(\mathrm{p}<.05)$;

$*$ two-tailed $<.05$.

\section{Discussion}

The results of this analysis indicated that nations whose residents had higher scores on the traits of agreeableness and neuroticism had lower economic growth in their GDP per capita from 2001 to 2005 . These results suggest 
that the personality of the residents of the nations of the world may have some impact on the economic activity and economic growth of those nations, as Lynn (1991) proposed.

In a previous study, Yang and Lester (2016) explored whether the Big 5 scores of residents of the 48 contiguous, continental states of the United States contributed to the prediction of economic activity in the states. By themselves, scores of the residents of the states on the Big 5 personality traits accounted for $26 \%$ of the variance in the gross state product and the gross state product per capita. Even after controls for economic variables, openness continued to be a consistent predictor of the gross state product, while extraversion and neuroticism were predictors of the gross state product per capita. This study of regions within a country has not been replicated in other federated nations that calculate economic indicators for each region of the nations, but this would be interesting in countries such as Australia, Canada or Spain.

The present study on nations found that neuroticism and agreeableness predicted economic growth in the sample of nations with available data. In their study of American states, Yang and Lester (2016) found that the neuroticism scores of the residents of the states were negatively associated with the gross state product per capita, but in the present study of nations, the association was positive. It appears therefore, that the correlates of economic performance may differ in studies of regions within a nation from the correlates over samples of nations.

Finally, it should be noted that, in their study of the American states, Yang and Lester (2016) introduced controls for other social-economic variables. Future research on the role of national character in the economic performance of nations should also include relevant socio-economic variables.

\section{References}

Bartram, D. (2013). Scalar equivalence of OPQ32: Big Five profiles of 31 countries. Journal of Cross-Cultural Research, 44, 61-83. https://doi.org/10.1177/0022022111430258

Cattell, R. B. (1990). Advances in Cattellian personality theory. In L. A. Pervin (Ed.), Handbook of personality (pp. 101-110). New York: Guilford.

Cloninger, C. R. (1986). A unified biosocial theory of personality and its role in the development of anxiety states. Psychiatric Developments, 3, 167-266.

Costa, P. T., \& McCrae, R. R. (1992). Revised NEG Personality Inventory (NEO-PI-R) and NEO Five-Factor Inventory (NEO-FFI) professional manual. Odessa, FL: Psychological Assessment Resources.

Eysenck, H. J. (1994). The Big Five or giant three. In C. F. Halverson, G. A. Kohnstamm \& R. P. Martin (Eds.), The developing structure of temperament and personality from infancy to adulthood (pp. 37-51). Hillsdale, NJ: L. Erlbaum Associates.

Furnham, A., Moutafi, J., \& Chamorro-Premuzic, T. (2005). Personality and intelligence. International Journal of Selection \& Assessment, 13, 11-24. https://doi.org/10.1111/j.0965-075X.2005.00296.x

Hofstede, G. (2001). Culture's consequences. Thousand Oaks, CA: Sage.

Johnson, J. P., \& Lenartowicz, T. (1998). Culture, freedom and economic growth. Journal of World Business, 33, 332-356. https://doi.org/10.1016/S1090-9516(99)80079-0

Lester, D., \& Yang, B. (2009). Two sources of human irrationality. Journal of Socio-Economics, 38, 658-662. https://doi.org/10.1080/00036846.2015.1085638

Lynn, R. (1991). The secret of the miracle economy. London, UK: The Social Affairs Unit.

McClelland, D. C. (1976). The achieving society. Princeton, NJ: Van Nostrand.

McRae, R. R. (2002). NEO-PI-R data from 36 cultures. In R. R. McRae \& J. Allik (Eds.), The five-factor model of personality across cultures (pp. 105-125). New York: Kluwer Academic.

McRae, R. R., \& Terracciano, A. (2005). Personality profiles of cultures. Journal of Personality \& Social Psychology, 89, 407-425. https://doi.org/10.1037/0022-3514.89.3.407

Schmitt, D. P., Allik, J., McRae, R. R., \& Benet-Martinez, V. (2007). The geographic distribution of Big Five personality traits. Journal of Cross-Cultural Psychology, 38, 173-212. https://doi.org/10.1177/0022022106297299

Schmitt, D. P., Realo, A., Voracek, M., \& Allik, J. (2008). Why can't a man be more like women? Sex differences in Big 5 personality traits across 55 cultures. Journal of Personality \& Social Psychology, 94, 168-182. https://doi.org/10.1037/0022-3514.94.1.168 
Schumpeter, J. A. (1934). The theory of economic development. Oxford, UK: Oxford University Press.

Seibert, S., \& Kraimer, M. (2001). The five-factor model of personality and career success. Journal of Vocational Behavior, 58, 1-21. https://doi.org/10.1006/jvbe.2000.1757

Steel, G. D., Rinne, T., \& Fairweather, J. (2012). Personality, nations, and innovation. Cross-Cultural Research, 46, 3-30. https://doi.org/10.1177/1069397111409124

Weber, M. (1929). The Protestant ethic and the spirit of capitalism. New York: Scribner.

Wiener, M, J. (1981). English culture and the decline of the industrial spirit 1850-1980. Cambridge, UK: Cambridge University Press.

Yang, B., \& Lester, D. (2016). Personality traits and economic activity. Applied Economics, 48, 653-657. https://doi.org/10.1080/00036846.2015.1085638

\section{Appendix}

The sample of nations with available data

\begin{tabular}{|c|c|c|}
\hline North America & Southern Europe & East Asia \\
\hline Canada & Cyprus & Hong Kong \\
\hline Mexico & Greece & Japan \\
\hline USA & Italy & Korea, Republic of \\
\hline South America & Malta & \\
\hline Argentina & Portugal & \\
\hline Bolivia & Spain & \\
\hline Brazil & Middle East & \\
\hline Chile & Israel & \\
\hline Peru & Jordan & \\
\hline Western Europe & Lebanon & \\
\hline Austria & Turkey & \\
\hline Belgium (Flanders) & Africa & \\
\hline Finland & Botswana & \\
\hline France & Congo (Democratic Republic of the) & \\
\hline Germany & Ethiopia & \\
\hline Netherlands & Morocco & \\
\hline Switzerland & South Africa & \\
\hline UK & Tanzania & \\
\hline Eastern Europe & Zimbabwe & \\
\hline Croatia & Oceania & \\
\hline Czech Republic & Australia & \\
\hline Estonia & Fiji \& Pacific Islands & \\
\hline Latvia & New Zealand & \\
\hline Lithuania & South \& Southeast Asia & \\
\hline Poland & Bangladesh & \\
\hline Romania & India & \\
\hline Serbia & Indonesia & \\
\hline Slovakia & Malaysia & \\
\hline Slovenia & Philippines & \\
\hline Ukraine & & \\
\hline
\end{tabular}

\section{Copyrights}

Copyright for this article is retained by the author(s), with first publication rights granted to the journal.

This is an open-access article distributed under the terms and conditions of the Creative Commons Attribution license (http://creativecommons.org/licenses/by/4.0/). 